\title{
Yenilenebilir Enerji, Çevre ve Ekonomik Büyüme iliş̧kisi: Seçilmiş Ülkeler için Ampirik Bir Analiz*
}

\begin{abstract}
çalışma, yenilenebilir enerji üretiminde dünya sıralamasında ilk beş içinde yer alan ülkeler için çevre kirliliği, yenilenebilir enerji üretimi ve gelir arasındaki uzun dönemli ilişkileri, dinamik panel veri yöntemleri kullanılarak 1992-2013 dönemi için incelemeyi amaçlamaktadır. Yatay kesit bağımlılık testi sonuçları, tüm değişkenler ve model için yatay kesit bağımlılığın olduğunu göstermektedir. Analiz sonuçları şu şekilde özetlenebilir: i) Durağan olmayan değişkenler arasında uzun dönemli bir ilişki mevcuttur. ii) Yenilenebilir enerji üretimi, çevre kirliliği üzerinde negatif bir etkiye sahiptir. iii) Kişi başı gelir, çevre kirliliği üzerinde pozitif etkiye sahiptir. İncelenen ülkelerde, yenilenebilir enerji üretiminin artışı, çevre kirliliğinin azaltılmasına ve iktisadi büyüme-çevre çatışmasının çözümüne katkıda bulunacaktır.
\end{abstract}

Anahtar Kelimeler: Yenilenebilir Enerji, Karbon Emisyonu, Enerji Ekonomisi, Panel Veri Analizi
Ali Acaravcl ${ }^{1}$

Sinan Erdoğan²

Renewable Energy, Environment and Economic Growth Nexus: An Empirical Analyses for Selected Countries

\section{Abstract}

The aim of this study is to examine the long run relationships between environmental pollution, renewable energy production and economic growth in pioneer countries on renewable energy production for 1992-2013 period by using dynamic panel data methods. Cross-sectional dependence test results indicate that there is an evidence of crosssection dependence for all variables and model. The results can be summarized as follows: i) There exists a cointegration relationship between nonstationary variables. ii) Renewable energy production has negative impact on the carbon emission. iii) Real GDP per capita has positive impact on carbon emission. The increase of renewable energy production is going to contribute to the solution of economic growth-environment conflict and reduction of environmental pollution in these countries.

Keywords: Renewable Energy, Carbon Emissions, Energy Economics, Panel Data Analysis

\section{Giriş}

18 ve 19. Yüzyılda İngiltere'de başlayan sanayi devrimi ile beraber buhar gücü insan gücünün yerini almış, kitle üretime dayalı iktisadi büyüme sürecinde temel gereksinimlerden birisi de enerji olmuştur. Enerji üretiminin ilk safhalarında çevre, insan merkezli düşünülmüş ve çevrenin insanlığın hizmetinde olması gerektiği düşüncesine dayanan "Antroposentrik" yaklaşım sergilenmiştir (Özerkmen, 2002). Çevre kirliliğinin artması ve daha da önemlisi çevre kirliliğinin insan sağlığını tehdit etmeye başlaması, çevre kirliliği ve doğal kaynakların korunması konusunu uluslararası bir tartışma konusu haline getirmiştir. 20. yüzyılın ikinci yarısına gelindiğinde iktisadi büyüme ile çevre arasında var olan çatışma etkisini daha güçlü hissettirmeye başlamıştır. Bu bağlamda gerek sorunların tespiti gerekse çözümü için uluslararası ölçekte Birleşmiş Milletler öncülüğünde birçok girişim olmuştur. Bu amaç doğrultusunda 1972 yılında düzenlenen Stockholm konferansının konu başlıklarından biri de "büyüme ve çevre" olmuş, fakat yayımlanan sonuç bildirgesi ülkeler açısından bağlayıcı nitelikte olmamıştır. 1987 Bruntland Raporu'nda ilk

\footnotetext{
* Bu çalışma 1.Uluslararası “ICEB 2016 2nd International Congress on Economics and Business" isimli kongrede sözlü olarak sunulmuştur.

${ }^{1}$ Prof., Mustafa Kemal Üniversitesi, İktisadi ve İdari Bilimler Fakültesi, íktisat Bölümü, acaravci@mku.edu.tr, http://orcid.org/0000-0002-6662-6175

${ }^{2}$ Arş. Gör., Mustafa Kemal Üniversitesi, i̇ktisadi ve İdari Bilimler Fakültesi, İktisat Bölümü, sinanerdogan@mku.edu.tr, http://orcid.org/0000-0003-3491-8234
} 
defa sürdürülebilir kalkınmadan bahsedilmiştir. Raporda "insanlık gelecek kuşakların gereksinimlerini tehlikeye atmadan sürdürülebilir kalkınma yeteneğine sahiptir" teması öne çıkmıştır (Our Common Future, 1987). 1992 yılında yine benzer amaçlarla Rio konferansı toplanmış ve beş konuda uzlaşma ortaya çıkmış olup bunlar; İklim Değişikliği Sözleşmesi, Biyolojik Çeşitlilik sözleşmesi, Rio Deklarasyonu, Gündem 21, Orman Prensipleri Raporu'dur. 1994 yılında günümüzde 195 ülkenin taraf olduğu sera gazlarının salınımlarını azaltmayı hedefleyen Birleşmiş Milletler İklim Değişikliği Çerçeve Sözleşmesi yürürlüğe konmuştur. Sözleşmeye taraf olan ülkeler sözleşmenin etkisinin güçlendirilmesi ve bağlayıcılığının arttırılması için Kyoto Protokolü üzerine müzakerelere başlamışlardır. 1997 yılında Kyoto Protokolü kabul edilmiş ve imzaya açılmıştır. Ancak protokolün yürürlüğe girmesi 2005 yılında Rusya'nın imzası ile mümkün olabilmiştir (UNFCCC, 2012). 2002 yılında Johannesburg'da "Dünya Sürdürülebilir Kalkınma” zirvesi gerçekleşmiştir. Zirve kapsamında çevre kirliliğindeki artışın devam ettiği, gelişmiş ve gelişmekte olan ülkelerde gelir dağılımı adaletinin giderek bozulduğu, küreselleşmenin fırsatlar ile beraber çeşitli sorunları da beraberinde getirdiği ve bu problemlerin çözümünde ortak inisiyatif vurgusu öne çıkmıştır. 2015 yılında, Paris İklim Zirvesi gerçekleştirilmiş ve dünya emisyonunun \%99.7'sini oluşturan 195 ülke, iklim değişikliği ile mücadele konusunda büyük bir uzlaşı sağlamıştır. Anlaşma, kapsam açısından çok geniş bir emisyon hacmi ve ülke grubunu kapsaması nedeniyle dönüm noktası olarak görülmüştür.

Görülmektedir ki 18. Yüzyıldan sonra başlayan ve yaklaşık olarak 2 yüzyıl boyunca iktisadi büyümenin öncelik olarak varsayıldığı iktisadi büyüme ve çevre çatışması sürecinde, doğal yaşamdaki ve çevresel bozulmaların geri dönülemez noktaya yaklaşması ile beraber, iktisadi büyüme politikaları sürdürülebilir kalkınma perspektifinde, çevre ve doğal yaşamı da gözetecek şekilde oluşturulmaya çalışılmaktadır (Vina, Hoff ve DeRose, 2002: 5-6). Bu noktada yapılan en büyük hamlelerden birisi de enerji üretiminde karbon temelli üretim teknolojisinin, yenilenebilir enerji üretimi teknolojisi ile ikame edilmesidir.

Karbon temelli enerji kaynaklarına alternatif olarak görülen yenilenebilir enerji üretim yöntemlerini 5 ana başlık altında toplamak mümkündür. Bunlar; Biyokütle, rüzgâr, güneş, su ve jeotermal enerjidir. Biyokütle yaşayan ya da yakın dönemde yaşamış organizmaları ifade etmektedir. Dünya'da biyokütle enerji potansiyelinin yıllık 2900 exajoule olduğu tahmin edilmektedir. Rüzgâr enerjisi rüzgâr gücü kullanılarak türbinler vasıtasıyla üretilmektedir. Dünya'da rüzgâr enerjisi potansiyelinin yıllık 6000 exajoule olduğu tahmin edilmektedir. Solar enerji en çok bilinen yenilenebilir enerji kaynaklarından biridir. Güneş panelleri vasıtasıyla gün ışığını enerjiye dönüştürmeyi hedefler. Ayrıca gün ışığı vasıtasıyla ısıtılan sıvıdan enerji üretmeyi hedefleyen solar termal enerji sistemleri de mevcuttur. Solar enerjinin yıllık potansiyelinin 3.900.000 exajoule olduğu tahmin edilmektedir.

Hidroelektrik enerjisi suyun debisinden enerji üretimi esasına dayanmaktadır. Potansiyelinin yıllık 150 exajoule olduğu tahmin edilmektedir. Görüldüğü üzere hidroelektrik enerjisi yenilenebilir enerji kaynakları arasında en düşük potansiyele sahip enerji kaynağıdır Jeotermal enerji yıllık 140.000 .000 exajoule potansiyeli ile yenilenebilir enerji kaynakları arasında en yüksek potansiyele sahip enerji kaynağıdır. Dünya'nın merkezinden gelen ısının kullanılması ile enerji üretimini hedeflemektedir (Rogner, 2000). 
Tablo 1: Dünya Yıllık Yenilenebilir Enerji Potansiyeli

\begin{tabular}{|l|c|}
\hline Enerji Kaynağı & Enerji Potansiyeli (Exajoule) \\
\hline Hidro Kaynaklar & 150 \\
\hline Biokütle/Bio Yakıt & 2.900 \\
\hline Rüzgâr Enerjisi & 6.000 \\
\hline Güneş Enerjisi & 3.900 .000 \\
\hline Jeotermal Enerji & 140.000 .000 \\
\hline 2014 Yılı Dünya Elektrik Enerjisi Tüketimi & 730,8 \\
\hline
\end{tabular}

Not: Tablo yazar tarafından oluşturulmuştur.

Özellikle enerji konusunda dışa bağımlı ülkeler açısından yenilenebilir enerji, ülkelerin öz kaynaklarının kullanımını teşvik etmesi, enerji ithalatının azaltılması yoluyla ödemeler dengesi açıklarının iyileştirilmesi, üretim sürecinde enerji girdi maliyetlerini düşürmesi ve aynı zamanda çevre ile çatışmayan üretim tekniklerini teşvik etmesi gibi nedenlerle önem arz etmektedir. Çevresel bozulmaların, yenilenebilir enerji üretimini zorunlu kılmasının yanı sıra, dünya nüfusunda meydana gelen hızlı artışa bağlı olarak artan enerji talebi, enerji arzının artırıması noktasında hem çevre ve doğal yaşam dengesinin gözetilmesini hem de mevcut talebi karşılamak amacıyla enerji arzının artışını zorunlu kılmıştır. Karbon temelli enerji kaynaklarının geleceğinin sorgulanması ve bu kaynaklar ile enerji üretiminin var olan çevre problemlerini geri dönülemez noktaya taşıması riski, enerji talebinin karşılanması konusunda yenilenebilir enerji üretimi önemli bir alternatif olmuştur. Bu bağlamda dünya genelinde enerji politikalarının oluşturulması noktasında uzun vadeli planların temel odak noktasını yenilenebilir enerji teşkil etmiştir. 2015 yılında Amerika tarafından açıklanan temiz enerji planına göre, elektrik santrallerinin ortaya çıkarttığı karbon gazı salınımın önümüzde ki 15 yıl içinde 3 te 1 oranında azaltılması hedeflenmektedir. Ancak hemen akabinde kömüre olan desteğin süreceğinin açıklanması, enerji arz ve talep politikalarında paradigma değişiminin uzun zaman dilimi gerektireceğinin bir göstergesi olmuştur. Diğer taraftan Avrupa Birliği de yenilenebilir enerji konusunda önemli adımlar atmıştır. 2013 yılında Avrupa birliği ülkelerinin toplam elektrik üretiminin \%25.4'lik kısmı yenilenebilir enerji kaynaklarından üretilmekte olup bu konuda Avusturya \%68.1 ile ilk sırada yer almaktadır. İsviçre ise \%61.8 ile ikinci sıradadır. Üye ülkeler, 2050 yılında karbon temelli enerjiden tamamen kurtulmayı amaçlamaktadır. Bu bağlamda üye ülkelerin 2020 yılına kadar enerji tüketimlerinin \%20'sini yenilenebilir enerji kaynaklarından karşılaması hedeflenmiştir. Almanya 2015 yılında \%32.6 'lık oran ile bu hedefi aşmıştır. (Eurostat, 2015; Jacobson vd., 2009).

\section{Ampirik Literatür}

Yaklaşık yarım asırlık süreçte, dünya enerji üretim ve tüketim politikaları gerek çevresel nedenlerle gerekse iktisadi nedenlerle büyük bir dönüşüm geçirmiş ve bu dönüşümün hem iktisadi hem de çevresel boyutları, politika uygulamalarının başarılı olup olmadığı, değiş̧en paradigmaya bağlı olarak yenilenebilir enerji üretimi ve tüketiminin karbon emisyonu üzerindeki etkisi birçok çalışmaya konu olmuştur. Ayrıca ülkelerin iktisadi büyüme deneyimlerinin çevre üzerindeki etkisi de bir diğer tartışma alanı olmuştur.

Yenilenebilir enerji üretim ve tüketiminin karbon emisyonu üzerindeki etkisini inceleyen çalışmalar Tablo 2' de sunulmuştur. Çalışmalardan elde edilen bulgular genel olarak değerlen- 
dirilir ise; çalışmaların yenilenebilir enerji tüketimi ve karbon emisyonu ilişkisi alanında yoğunlaştığı görülmektedir. Bu bağlamda bakıldığında yenilenebilir enerji tüketiminin karbon emisyonu üzerindeki etkisi konusunda bir uzlaşı bulunmamakta olup üretim penceresinden bakıldığında ise öncelikle yenilenebilir enerji üretiminin karbon emisyonu üzerindeki etkisinin negatif olduğu söylenebilir. Diğer taraftan bu alandaki literatürün henüz gelişmekte olduğu ve bu alanda yapılan çalışmaların genel olarak zaman serisi analizine dayalı olduğu görülmektedir.

Tablo 2: Literatür Tablosu

\begin{tabular}{|c|c|c|c|}
\hline \multicolumn{4}{|c|}{ Yenilenebilir Yenilenebilir Enerji Tüketimi-Karbon Emisyonu İlişkisini İnceleyen Çalışmalar } \\
\hline Yazar (lar) & Örneklem (Dönem) & Yöntem & Sonuç \\
\hline $\begin{array}{l}\text { Menyah ve Wolde-Rufael } \\
\qquad(2010)\end{array}$ & $\begin{array}{c}\text { ABD } \\
(1960-2007) \\
\end{array}$ & Zaman Serisi Analizi & Anlamlı İlişki Yok \\
\hline $\begin{array}{l}\text { Apergis vd. } \\
\text { (2010) }\end{array}$ & $\begin{array}{l}19 \text { Gelişmiş ve Gelişmekte } \\
\text { Olan Ülke (1984-2007) }\end{array}$ & Panel Veri Analizi & Pozitif Etki \\
\hline $\begin{array}{l}\text { Farhani ve Shahbaz } \\
\qquad(2014)\end{array}$ & $\begin{array}{c}10 \text { MENA Ülkesi } \\
(1980-2009) \\
\end{array}$ & Panel Veri Analizi & Pozitif Etki \\
\hline $\begin{array}{l}\text { Bölük ve Mert } \\
\text { (2014) } \\
\end{array}$ & $\begin{array}{c}16 \text { Avrupa Birliği Ülkesi } \\
(1990-2008) \\
\end{array}$ & Panel Veri Analizi & Pozitif Etki \\
\hline $\begin{array}{l}\text { Shafiei ve Salim } \\
\qquad(2014)\end{array}$ & $\begin{array}{l}\text { OECD Ülkeleri } \\
(1980-2011)\end{array}$ & Panel Veri Analizi & Negatif Etki \\
\hline $\begin{array}{l}\text { Jaforullah ve King } \\
\qquad(2015)\end{array}$ & $\begin{array}{c}\text { ABD } \\
(1965-2012) \\
\end{array}$ & Zaman Serisi Analizi & Negatif Etki \\
\hline $\begin{array}{l}\text { Bilgili vd. } \\
\text { (2016) }\end{array}$ & $\begin{array}{c}17 \text { OECD Ülkesi } \\
(1977-2010) \\
\end{array}$ & Panel Veri Analizi & Negatif Etki \\
\hline \multicolumn{4}{|c|}{ Yenilenebilir Yenilenebilir Enerji Üretimi-Karbon Emisyonu iliş̧isini İnceleyen Çalışmalar } \\
\hline Yazar (lar) & Örneklem (Dönem) & Yöntem & Sonuç \\
\hline $\begin{array}{c}\text { Bölük ve Mert } \\
\text { (2015) }\end{array}$ & $\begin{array}{c}\text { Türkiye } \\
\text { (1961-2010) }\end{array}$ & Zaman Serisi Analizi & Negatif Etki \\
\hline $\begin{array}{l}\text { Bento ve Moutinho } \\
\qquad(2016)\end{array}$ & $\begin{array}{c}\text { İtalya } \\
(1960-2011)\end{array}$ & Zaman Serisi Analizi & Negatif Etki \\
\hline
\end{tabular}

Not: Tablo yazar tarafından oluşturulmuştur.

Çalışma öncelikle politika bağlamında Stockholm Konferansı'ndan bu yana karbon emisyonu azaltma çabalarının, yenilenebilir enerji arzı bağlamında başarısını irdeleme amacı taşımaktadır ve yenilenebilir enerji üretimi-karbon emisyonu ilişkisini panel veri yöntemleri ile alması ile bu alanda gelişmekte olan literatüre özgün bir katkı yapmayı amaçlamaktadır. Bu amaç doğrultusunda çalışmada, yenilenebilir enerji üretiminde dünya sıralamasında ilk beş içinde yer alan ülkeler için yenilenebilir enerji üretimi ve kişi başı reel gelirin karbon emisyonu üzerindeki etkisi, 1992-2013 dönemi için incelenmiştir. Çalışmada, panel veri ekonometrisi alanında son yıllarda 
geliştirilmiş ve daha güvenilir sonuçlar veren, serilerin ve modelin yatay-kesit bağımlılık özelliklerini dikkate alan ve her bir kesit için heterojen katsayılar hesaplamaya olanak sağlayan panel veri analizi yöntemleri kullanıımıştır. Çalışmanın ikinci kısmında model, örneklem, yöntem ve uygulama sonuçları; son kısımda sonuç ve politika önerileri yer almaktadır.

\section{Model, Örneklem, Yöntem ve Uygulama Sonuçları}

\subsection{Model ve Örneklem}

Bu çalışmada; yenilenebilir enerji üretiminde öncü beş ülke (U.S. Energy Information Administration, 2015) için karbon emisyonu, yenilenebilir enerji üretimi ve kişi başı milli gelir arasındaki uzun dönemli ilişkiler, panel veri analizi yöntemiyle araştırılmaktadır. Yenilenebilir enerji üretimi ve kişi başı milli gelirdeki değişimlerin karbon emisyonu üzerindeki etkisini araştırmak amacıyla aşağıdaki logaritmik-doğrusal model kullanılacaktır:

$$
c o_{i t}=\beta_{i}+\beta_{1} \text { ren }_{i t}+\beta_{2} g d p_{i t}+\varepsilon_{i t}
$$

Burada $\mathrm{i}=1,2 \ldots, 5$ ve $\mathrm{t}=1,2, \ldots, 22^{\prime}$ dir. Model, 1992-2013 yılları arasında eksiksiz veriye sahip olan beş ülke (Brezilya, Kanada, Çin, Rusya ve Amerika Birleşik Devletleri) için test edilmiştir. Modelde yer alan co değişkeni kişi başı karbon emisyonu, ren değişkeni kişi başına düşen yenilenebilir elektrik enerjisi üretimi miktarı (hidro kaynaklardan üretilmiş elektrik enerjisi olmaksızın) ve $g d p$ değişkeni ise kişi başı reel GSYH' dır (2005 \$ fiyatlarından). Veriler, Dünya Bankası Dünya Gelişme Göstergeleri çevrimiçi veri tabanından (World Bank World Development Indicators Online Database) alınmıştır. Modelde yer alan kişi başı yenilenebilir elektrik enerjisi üretimi miktarı, hidroelektrik üretimi miktarını kapsamamakta olup, ülkeler bazında toplam yenilenebilir elektrik enerjisi üretiminin, ilgili ülkelerin nüfusuna oranlanması ile elde edilmiştir. Değişkenlerin doğal logaritması alınarak model doğrusal hale getirilmiştir.

\subsection{Yöntem ve Uygulama Sonuçları}

Dinamik panel veri analizinde değişkenler için birim kök testleri ve eşbütünleşme testleri yatay-kesit bağımlılık ilişkisine duyarlıdır. Panel veri analizinde değişkenlerde veya modelde yer alan yatay kesit bağımılığın göz ardı edilmesi, sapmalı tahminlere neden olabilmektedir. Bu nedenle değişkenler arasında veya modelde yatay-kesit bağımlıı̆̆ın araştırılması amacıyla ilk olarak $C D_{L M 1}$ (Breusch ve Pagan, 1980) ve $C D_{L M 2}$ (Pesaran, 2004) testleri uygulanmıştır. Paneli oluşturan birimler arasında yatay-kesit bağımlılık olmasından dolayı değişkenlerin durağanlık özellikleri Smith vd. (2004) Bootstrap birim kök testi ile araştırılmıştır. Durağan olmayan ve yataykesit bağımlılık içeren değişkenler arasındaki uzun dönemli ilişkinin varlığını test etmeye yönelik olarak Westerlund'un (2008) Durbin-Hausman testi uygulanmıştır. Modelde yer alan değişkenlerin uzun dönemli katsayılarının hesaplanmasında ise AMG yöntemi (Augmented Mean Group estimetor-Arttırılmış Ortalama Grup tahmincisi (Eberhardt ve Bond, 2009; Eberhardt ve Teal 2010; Eberhardt ve Teal, 2011)) kullanılmıştır.

\subsubsection{Yatay Kesit Bağımlılık ve Eğim Katsayıları Homojenliği Test Sonuçları}

Breucsh-Pagan'ın (1980) $L M\left(C D_{L M 1}\right)$ testi, panelin zaman boyutunun kesit boyutundan büyük olduğu ( $T>N$ ) durumlarda etkin sonuçlar vermekte olup, hipotezlerin test edilmesinde kullanılan lagrange çarpanı aşağıdaki formülle hesaplanmaktadır:

$$
L M=T \sum_{i=1}^{N-1} \sum_{j=i+1}^{N} \hat{p}_{i j}^{2}: \frac{X^{2} N(N-1)}{2}
$$


Pesaran'ın (2004) $C D_{L M 2}$ testi, zaman boyutunun kesit boyutundan mutlak olarak büyük olduğu $(\mathrm{T}>\mathrm{N})$ durumlarda kesitler arası korelasyonun varlığını araştırmakta olup, hipotezlerin test edilmesinde kullanılan lagrange çarpanı aşağıdaki formülle hesaplanmaktadır:

$$
C D_{L M 2}=\left(\frac{1}{N(N-1)}\right)^{1 / 2} \sum_{i=1}^{N-1} \sum_{j=i+1}^{N}(T \hat{p} i j-1)
$$

$C D_{L M 1}$ ve $C D_{L M 2}$ test istatistikleri, aşağıdaki hipotezlerin sınanmasında kullanılmaktadır:

$H_{0}$ : Yatay kesit bağımlılık yoktur.

$H_{1}$ : Yatay kesit bağımlılık vardır.

Tablo 3'e göre yatay kesit bağımlılık yoktur görüşü, her iki testte de farklı olasılık düzeylerinde hem değişkenler hem de model açısından ret edilmektedir. Değişkenler için yatay kesit bağımlılı̆ın varlığının kabul edilmesi, modelde yer alan ülkelere ait değişkenlerin birinde yaşanacak bir değişmenin diğer ülkelerin ilgili değişkenini etkilediğini göstermektedir. Bu durum, Stockholm konferansından bu yana çevre ve iklim değişikliğine dair atılan ortak hareketlerin bir uzantısı olarak nitelendirilebilir. Bu bağlamda, ülkelerin karbon emisyonunu azaltma yönünde uluslararası anlaşmalarla verdiği taahhütlerin karşılıklı bir bağımlılık olgusu yarattığı söylenebilir. Ayrıca yenilenebilir enerji üretimi konusunda ortaya çıkan bu karşılıklı ilişki, karbon emisyonunda mevcut olan karşılıklı bağımlılığın bir sonucu olarak değerlendirilebilir. Ayrıca kişi başı reel gelirde ortaya çıkan bu karşılıklı etkileşim, küreselleşme olgusunun bir uzantısı olduğu söylenebilir. Analizde kullanılan değişkelerin ve modelin yatay kesit bağımlılık içermesi, yatay kesit bağımlılığı dikkate alan birim kök testlerinin ve eşbütünleşme testlerinin kullanılmasını zorunlu kılmaktadır. Modelde kapsamında hesaplanacak olan eğim katsayıların homojen olup olmadığını test etmek amacıyla Pesaran vd. (2008) tarafından geliştirilen delta testleri ( $\nabla^{(}$ve $\&_{a d j}$ ) kullanılmış; modeldeki eğim katsayılarının homojen olduğu görüşü her iki testte de güçlü bir biçimde reddedilmiştir.

Tablo 3: Yatay Kesit Bağımlılık ve Katsayı Homojenliği Test Sonuçları

\begin{tabular}{lcccc}
\hline CD testleri & co & ren & gdp & model \\
\hline $\mathrm{CD}_{\mathrm{LM} 1}$ & $24,174(0,007)$ & $25,583(0,004)$ & $21,031(0,021)$ & $35,127(0,000)$ \\
$\mathrm{CD}_{\mathrm{LM} 2}$ & $3,169(0,001)$ & $3,485(0,000)$ & $21,031(0,007)$ & $35,127(0,000)$ \\
\hline$Q_{\mathrm{C}}$ & $12,332(0,000)$ & & $Z_{\text {adj }}$ & $13,568(0,000)$ \\
\hline
\end{tabular}

Not: Parantez içindeki değerler, olasılık değerleridir.

\subsubsection{Durağanlık Analizi Sonuçları}

Smith $v d$. (2004) testi, yöntemsel olarak Im vd. (2003) tarafından geliştirilen birim kök testine dayanmaktadır ve yatay kesit bağımlılık bootstap yaklaşımı ile modellenmektedir ve $t$ istatistikleri bireysel ADF istatistiklerinin ortalaması ile elde edilmektedir (4 numaralı denklem). Standartlaştırılmış $\mathrm{t}$ istatistiği ise 5 numaralı denklemde gösterildiği gibi elde edilmektedir.

$$
\begin{aligned}
& t^{*}=N^{-1} \sum_{I=1}^{N} t_{i} \\
& \bar{t}_{s}=\frac{\sqrt{N}\left\{\bar{t}-E\left(t_{i}\right)\right\}}{\sqrt{\operatorname{Var}\left(t_{i}\right)}}
\end{aligned}
$$


Test kapsamında sınanan hipotezler aşağıdaki gibidir:

$H_{0}$ : Birim kök vardır.

$H_{1}$ : Birim Kök Yoktur.

Tablo 4'te görüldüğü üzere tüm değişsenlerin yalnızca sabitli ve hem trend hem de sabitli modelde birim kök içerdiği hipotezi güçlü bir biçimde kabul edilmektedir. Bu bağlamda ilgili değişkenlerde muhtemel bir şokun etkisi kalıcı olmaktadır ve seriler kendiliğinden denge değerlerine dönememektedir. Değişkenlerin birinci farkları alındığında ise farklı olasılık seviyelerinde durağan hale gelmektedir.

Tablo 4: Smith vd. Bootstrap Panel Birim Kök Test Sonuçları

\begin{tabular}{ccccc}
\hline \multirow{2}{*}{ Model } & \multicolumn{2}{c}{ Düzey } & \multicolumn{2}{c}{ 1. Fark } \\
\cline { 2 - 5 } & Trend ve Sabit & Sabit & Trend ve Sabit & Sabit \\
\hline Değişkenler & IPS İstatistiği & IPS İstatistiği & IPS İstatistiği & IPS İstatistiği \\
\hline co & $-2,041(0,587)$ & $-0,350(0,983)$ & $-3,075(0,028)$ & $-2,404(0,026)$ \\
ren & $-1,159(0,989)$ & $-0,112(0,943)$ & $-3,549(0,004)$ & $-3,007(0,001)$ \\
gdp & $-1,924(0,628)$ & $-2,966(0,048)$ & $-3,259(0,040)$ & $-2,588(0,018)$ \\
\hline
\end{tabular}

Not: Gecikme uzunluğu 2 olarak alınmış olup olasılık değerleri 10000 bootstrap dağılımından elde edilmiş ve parantez içinde gösterilmiştir.

\subsubsection{Eşbütünleşme Test Sonuçları}

Çalışmada; değişkenler arası uzun dönemli ilişkilerin varlığını test etmeye yönelik olarak Durbin-Hausman eşbütünleşme testi kullanılmıştır. Testin uygulanmasından bağımlı değişkenin durağan olmaması zorunlu olup, açıklayıcı değişkenlerden bazıları durağan olabilmektedir. Ayrıca, bu test, yatay kesit bağımlılığı dikkate almakta olup, hesaplanacak eğim katsayılarının hem homojen olduğu hem de heterojen olduğu durumlarda kullanılabilmektedir (Westerlund, 2008: 196-199). Katsayıların heterojen olması durumunda dikkate alınan grup istatistiği ise 6 numaralı denklemdeki gibi hesaplanmakta olup, sınanan hipotezler aşağıdaki gibidir:

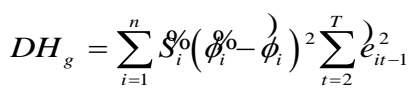

$H_{0}$ : Bütün birimler için eşbütünleşme yoktur.

$\mathrm{H}_{1}$ : Bazı birimler için eşbütünleşme vardır

Durbin-Hausman testi kapsamında heterojen eğim katsayılarının varlığı görüşüne dayanan $d h \_g$ istatistiği dikkate alınmaktadır. Bu bağlamda modelde yer alan bazı birimler arasında eşbütünleşmenin varlığı görüşü $d h \_g$ istatistiğine göre $\% 10$ anlamlılık düzeyinde kabul edilmektedir. Bu sonuca göre değişkenler arasında eşbütünleşme ilişkisinin varlığı, yani uzun dönemde bir birlikte hareketin söz konusu olduğu anlamına gelmektedir.

Tablo 5: Panelde Yer Alan Ülkeler için Durbin-Hausman Eşbütünleşme Test Sonucu

\begin{tabular}{ccc}
\hline Test & İstatistik & Olasılık Değeri \\
\hline dh_g & $-1,524$ & 0,064 \\
\hline
\end{tabular}




\subsubsection{Uzun Dönemli Katsayılar}

Uzun dönemli katsayıların hesaplanmasında, yatay kesit bağımlılığı ve heterojen eğim katsayıları hesaplanmasına olanak sağlayan AMG (Arttırılmış Ortalama Grup tahmincisi, Augmented Mean Group estimator (Eberhardt \& Bond, 2009; Eberhardt \& Teal, 2010,2011)) yöntemi kullanılmıştır. Ayrıca AMG yöntemi kapsamında değişkenlerin eşbütünleşme derecelerinin aynı olması şartı bulunmamakta, içsellik bulunması durumunda dahi tutarlı ortak veya heterojen katsayılar tahminine olanak sağlamaktadır. Tablo 6'da yer alan sonuçlara göre modelde yer alan ülkeler AMG tahmincisi ile yapılmış uzun dönemli katsayı tahmin sonuçlarına göre yenilenebilir elektrik enerjisi üretimi, kişi başı milli gelir ve karbon emisyonu arasında uzun dönemli anlamlı bir ilişki bulunmaktadır. Bu bağlamda yenilenebilir elektrik üretiminde yaşanacak bir artışın panelde yer alan ülkelerde karbon emisyonunu azaltması beklenebilir. Diğer taraftan kişi başı milli gelirde bir artışın panelde yer alan ülkelerde karbon emisyonunu artırması beklenebilir.

Tablo 6 :Uzun Dönemli Katsayı Tahmin Sonuçları

\begin{tabular}{|c|c|c|c|c|}
\hline & Açıklayıcı Değişkenler & Katsayılar & t-istatistiği & Olasılık Değeri \\
\hline \multirow{4}{*}{ Panel } & ren & $-0,079$ & $-2,53$ & 0,011 \\
\hline & gdp & 0,976 & 4,04 & 0,000 \\
\hline & sabit & $-23,516$ & $-3,34$ & 0,001 \\
\hline & Wald istatistiği & & 24,440 & 0,000 \\
\hline \multirow{3}{*}{ Brezilya } & ren & 0,014 & 0,10 & 0,919 \\
\hline & gdp & 0,797 & 1,41 & 0,160 \\
\hline & sabit & $-22,096$ & $-0,168$ & 0,093 \\
\hline \multirow{3}{*}{ Kanada } & ren & $-0,037$ & $-3,13$ & 0,002 \\
\hline & gdp & 1,379 & 5,14 & 0,000 \\
\hline & sabit & $-32,283$ & $-4,31$ & 0,000 \\
\hline \multirow{3}{*}{ Çin } & ren & $-0,066$ & $-1,68$ & 0,094 \\
\hline & $\mathrm{gdp}$ & 1,669 & 5,56 & 0,000 \\
\hline & sabit & $-44,242$ & $-5,70$ & 0,000 \\
\hline \multirow{3}{*}{ Rusya } & ren & $-0,047$ & $-3,12$ & 0,002 \\
\hline & $\operatorname{gdp}$ & 0,703 & 14,71 & 0,000 \\
\hline & sabit & $-16,049$ & $-13,63$ & 0,000 \\
\hline \multirow{3}{*}{$A B D$} & ren & $-0,159$ & $-10,47$ & 0,000 \\
\hline & gdp & 0,329 & 3,99 & 0,000 \\
\hline & sabit & $-2,909$ & $-1,08$ & 0,282 \\
\hline
\end{tabular}

Tablo 6'da aynı zamanda ülke bazlı sonuçlar da yer almaktadır. Buna göre Kanada, Çin, Rusya ve $A B D$ 'de yenilenebilir elektrik enerjisi üretimi, kişi başı milli gelir ve karbon emisyonu arasında anlamlı ilişki bulunmuştur. Buna göre yenilenebilir elektrik enerjisi üretiminde yaşanacak artışın karbon emisyonunu azaltması beklenebilir. Diğer taraftan kişi başı milli gelirde yaşanacak bir 
artışın karbon emisyonunu artırması beklenebilir. Ülke bazlı sonuçlara göre Brezilya'da yenilenebilir elektrik enerjisi üretimi, kişi başı milli gelir ve karbon emisyonu arasında anlamlı ilişki bulunmamaktadır.

\section{Sonuç}

Bu çalışmada, yenilenebilir enerji üretiminde dünya sıralamasında ilk beş içinde yer alan ülkeler için çevre kirliliği, yenilenebilir enerji üretimi ve gelir arasındaki uzun dönemli ilişkileri, yatay kesit bağımlılığı dikkate alan dinamik panel veri yöntemleri kullanılarak 1992-2013 dönemi için incelenmiştir. Çalışmanın ekonometrik analiz kısmından elde edilen genel sonuçları, aşağıdaki gibi özetlemek mümkündür:

i) Tüm değişkenler ve model için yatay kesit bağımlıık söz konusudur. Çevre kirliliği, yenilenebilir enerji üretimi ve kişi başı reel gelir değişkenleri ülkeler arasında etkileşim içerisindedir. Bir ülke ortaya çıkan bir gelişme diğer ülkeleri de etkilemektedir.

ii) Tüm değişkenler fark durağandır ve bu değişkenler arasında uzun dönemli bir ilişki mevcuttur. Yenilenebilir enerji üretimi, çevre kirliliği üzerinde negatif bir etkiye ve kişi başı gelir, çevre kirliliği üzerinde pozitif etkiye sahiptir.

Yenilenebilir enerji üretiminin, karbon emisyonu üzerinde negatif etkiye sahip olması; Bölük ve Mert (2015) ile Bento ve Moutinho (2016)' un ulaştığı sonuçları destekler niteliktedir. Bu bağlamda ilgili ülkelerin enerji üretim politikalarının, yenilenebilir enerji üretimini hidro kaynaklar olmaksızın teşvik edecek şekilde oluşturulması karbon salınımının kontrolü ve azaltılmasının yanı sıra temiz su kaynaklarının korunması adına kritik öneme sahiptir. Bu husus yalnızca analize konu ülkeler için değil tüm ülkeler için sürdürülebilir ekonomik büyüme ve kalkınma noktasında önemlidir.

Stockholm konferansından bu yana çevre ve iktisadi büyüme ilişkisi konusunda süre gelen tartışmalar; son yıllarda karbon temelli enerji kaynaklarının geleceğinin sorgulanır hale gelmesi, çevre bilinci artışına bağlı olarak karbon salınım miktarının azaltılması hedefine bağlı olarak, yenilenebilir enerji üretiminin enerji arz politikalarının odak noktasına yerleşmesiyle yeni bir boyuta taşınmıştır. Karbon salınımına bağlı olarak çevre kirliliğinin "geri döndürülemez" nokta olarak adlandırılan kritik seviyelere yaklaşmış olması, çevre kirliliği ile mücadeleyi destekleyecek bir enerji arz politikası oluşturulmasını zorunlu kılmaktadır. Ayrıca doğal yaşam döngüsünün devamı için sürdürülebilir temiz su arzı adına, hidro kaynakların enerji üretiminde kullanılması da bir diğer tartışma alanı olmuştur. Afrika kıtasının kimi bölgelerinde kabileler arasında su için savaşların yaşanması, enerji üretimi konusunda en düşük potansiyele sahip kaynağın hidro kaynaklar olduğu gibi etkenler göz önünde bulundurulduğunda, hidro kaynakların doğal yaşam döngüsünün devamı için kullanılması hususu salt analizde ele alınan ülkeler adına değil tüm dünya adına önem arz etmektedir. Gerek çevre kirliliği ile mücadele, gerek sürdürülebilir temiz su arzı adına hidro kaynaklar olmaksızın yenilenebilir enerji üretimi, Stockholm konferansı ile beraber başlayan çevre ile uyumlu iktisadi büyüme modellerinin tesisi sürecinin başarıya ulaşması noktasında tüm ülkeler için büyük bir öneme sahiptir.

Illgili ülkelerde iktisadi büyümenin karbon emisyonu üzerinde pozitif etkiye sahip olması, ilgili ülkelerin çevreyi kirletmek pahasına iktisadi büyümeyi gerçekleştirdiği konusunda fikir vermektedir. Bu durum Birleşmiş Milletler tarafından 1996 yılında yayınlanan İnsani Kalkınma Raporu'nda (United Nations, 1996) "Geleceksiz Büyüme” olarak tanımlanan iktisadi büyüme sürecine işaret etmektedir. Bu bağlamda ilgili ülkeler açısından iktisadi büyüme politikalarının çevre 
koruma politikaları ile uyumlulaştırılması, karbon emisyonunun kontrol edilmesi ve azaltılması adına önemlidir.

Son olarak; Paris İklim Sözleşmesi'nin önemli taraflarından birisi olan Amerika Birleşik Devletleri'nin anlaşmadan 2017 yılı itibariyle çıkacağını açıklamış olması, küresel ısınma ile mücadele için karbon emisyonunun azaltılması konusunda bir kırılma noktası olarak değerlendirilebilir. Bu nedenle araştırmanın gelecekte yapılacak çalışmalarda bu kırılmayı da dikkate alarak genişletilmesi önem arz etmektedir. 


\section{Kaynaklar}

Apergis, N., Payne, E. J., Menyah, K., Wolde-Rufael, Y. (2010). On the Casual Dynamics Between Emissions, Nuclear Energy, Renewable Energy and Economic Growth. Ecological Economics, 69: 2255-2260.

Bento, J. P. C., Moutinho, V. (2016). Co2 Emissions, Non-Renewable and Renewable Electricity Production, Economic Growth, and International Trade in Italy. Renewable and Sustainable Energy Reviews, 55: 142-155.

Bilgili, F., Koçak, E., Bulut, Ü. (2016). The Dynamic Impact of Renewable Energy Consumption on Co2 Emissions: A Revisited Environmental Kuznets Curve Approach. Renewable and Sustainable Energy Reviews, 54: 838-845.

Bölük, G., Mert, M. (2014). Fossil \& Renewable Energy Consumption, GHG's (Greenhouse Gasses and Economic Growth: Evidence from a Panel of EU (European Union) Countries. Energy, 74: 439-446.

Bölük, G., Mert, M. (2015). The Renewable Energy, Growth and Environmental Kuznets Curve in Turkey: An ARDL Approach. Renewable and Sustainable Energy Reviews, 52: 587-595.

Breusch, P. S.; Pagan, A. R. (1980). The Lagrange Multiplier Test and It's Applications to Model Specification in Econometrics. Review of Economic Studies, 11(7); 239-253.

Brutland G. H. (1987). Our Common Future. Report of the World Comission on Environment and Development: 41.

Eberhardt, M., Bond, S. (2009) “Cross-Section Dependence in Nonstationary Panel Models: A Novel Estimator. MPRA Paper 17692, University Library of Munich. http://mpra.ub.unimuenchen. de/17692.pdf. (Erişim Tarihi: 11.12.2015).

Eberhardt, M., Teal F. (2010). Productivity Analysis in Global Manufacturing Production. Discussion Paper 515, Department of Economics, University of Oxford.

http://www.economics.ox.ac.uk/research/WP/pdf/paper515.pdf. (Erişim Tarihi: 11.12.2015).

Eberhardt, M., Teal F. (2011). Econometrics for Grumblers: A New Look at the Literature on Crosscountry Growth Empirics. Journal of Economic Surveys, 25; 109-155.

Eurostat (2015). Renewable Energy Statistics. http://ec.europa.eu/eurostat/statistics-explained/index.php/Renewable_energy_statistics (Erişim Tarihi: 29.03.2016).

Farhani, S., Shahbaz, M. (2014). What Role of Renewable and Non-Renewable Electricity Consumption and Output is Needed to Initially Mitigate Co2 Emissions in MENA Region. Renewable and Sustainable Energy Reviews, 40: 8090.

Global Energy Statistical Yearbook (2015). Electricity Domestic Consumption. https://yearbook.enerdata.net/electricity-domestic-consumption-data-by-region.html (Erişim Tarihi: 29.03.2016).

Im, Kyung So,; Pesaran, M. Hasheem,; Shin, Yongcheol (2003). Testing for Unit Roots in Heterogenius Panels. Journal of Econometrics, 115; 53-74.

Jacobsson, S., Bergek, A., Finon D., Lauber V., Mitchell, C., Toke D., Verbruggen, A. (2009). EU Renewable Energy Support Policy: Faith or Facts? http://www.diva-portal.org/smash/get/diva2:222137/FULLTEXT01.pdf (Erişim Tarihi: 29.03.2016).

Jaforullah, M., King, A. (2015). Does Use of Renewable Energy Sources Mitigate Co2 Emissions? A Reassessment of the US Evidence. Energy Economics, 49: 711-717.

La Vina,Antonio G. M., Hoff,Gretchen and DeRose, Anne Marie (2002). The Successes and Failures of Johannesburg: A Story of Many Summits. World Resources Institute 1-24. http://pdf.wri.org/wssd_joburg_english.pdf (Erişim Tarihi: 02.06.2014).

Menyah, K., Rufael-Wolde, Y. (2010). Co2 Emissions, Nuclear Energy, Renewable Energy and Economic Growth in the US. Energy Policy, 38: 2911-2915.

Özerkmen, N. (2002). İnsan Merkezli Çevre Anlayışından Doğa Merkezli Çevre Anlayışına. Ankara Üniversitesi Dil ve Tarih-Coğrafya Fakültesi Dergisi, 42(1-2): 167-185.

Pesaran, M. Hashem (2004). General Diagnostic Tests for Cross-Section Dependence in Panels. Journal of Applied Econometrics, 20, 264-309.

Pesaran, M. Hasheem; Ullah, Aman; Yamagata, Takashi (2008). A Bias-Adjusted LM Test for Error Cross-Section Independence. Econometrics Journal, 11; 105-127.

Rogner, H. H. (2000). Enegy Resources. Energy and Chanllenge of Sustainability,; 166.

Shafiei, S., Salim, R. A. (2014). Non-Renewable and Renewable Energy Consumption and Co2 Emissions in OECD Countries: A Comparative Analysis. Energy Policy, 66: 547-556. 
Eskişehir Osmangazi Üniversitesi iiBF Dergisi

Smith, L. Vanessa; Leybourne, Stephen; Kim, Tae-Hwan; Newbold, Paul (2004). More Powerful Panel Data Unit Root Tests with an Application to Mean Reversion in Real Exchange Rates. Journal of Applied Econometrics, 19; 147-170.

United Nations (1996). Human Development Report http://hdr.undp.org/sites/default/files/reports/257/hdr_1996_en_complete_nostats.pdf (Erişim Tarihi: 10.04.2016).

United Nations Framework Convention on Climate Changes, (2012). Kyoto Protocol. http://unfccc.int/kyoto_protocol/items/2830.php (Erişim Tarihi: 05.06.2014).

United States Energy Information Administration (2015). http://www.eia.gov/cfapps/ipdbproject/IEDIndex3.cfm (Erişim Tarihi: 15.12.2015)

U.S. Energy Information Administration (2015). Electricity.

https://www.eia.gov/electricity/data.cfm (Erişim Tarihi: 10.12.2015).Westerlund, Joakim (2008). Panel Cointegration Tests of the Fisher Effects. Journal of Applied Econometrics, 23; 193-233. 